\title{
A Simplified Approach to Link Course Learning Outcomes to Student Outcomes in ABET Accreditation to Perform Program Assessment and Improvement
}

\author{
Rahim Jassim ${ }^{1}$, Hazim Moria ${ }^{2}$, Saji $\operatorname{Varghase}^{2}$, Salem Aletani ${ }^{2}$, Yasir Hadi ${ }^{2}$ \\ ${ }^{1}$ Technical Department, Saudi Electric Services Polytechnic, Baish, Jazan, Kingdom of Saudi Arabia \\ ${ }^{2}$ Planning and Development Department, Yanbu Industrial College, Yanbu Industrial City, Kingdom of Saudi Arabia
}

\section{Email address:}

r_jassim@sesp.edu.sa (R. Jassim), moriah@rcyci.edu.sa (H. Moria), varghases@rcyci.edu.sa (S. Varghase), aletanis@rcyci.edu.sa (S. Aletani), hadiy@rcyci.edu.sa (Y. Hadi)

\section{To cite this article:}

Rahim Jassim, Hazim Moria, Saji Varghase, Salem Aletani, Yasir Hadi. A Simplified Approach to Link Course Learning Outcomes to Student Outcomes in ABET Accreditation to Perform Program Assessment and Improvement. Education Journal.

Vol. 6, No. 6, 2017, pp. 196-199. doi: 10.11648/j.edu.20170606.15

Received: August 31, 2017; Accepted: October 14, 2017; Published: December 7, 2017

\begin{abstract}
Assessment of student outcomes remains the most crucial issue in any plan that aims to address the requirements of ABET 2000. All specialization courses offered in the department should meet the required and pre-defined student outcomes. The achievement of these student outcomes indicates that the students achieved the program objectives. In this paper a simplified approach is described to assess the degree of achievement of the student outcomes through the direct assessment methods.
\end{abstract}

Keywords: Course Learning Outcomes, Student Outcomes, Program Assessment, Students' Achievement, ABET

\section{Introduction}

Student outcomes describe what students are expected to know, do, or think by graduation. Student outcomes must embrace Criterion 3 (a)-(k) and the Mechanical Engineering Associate degree program requirements. The achievement of student outcomes should indicate students achievement of educational objectives. Many programs have developed their own strategies to achieve student outcomes and consequently educational objectives. Student outcomes need not be limited to those specified in the ABET criteria [1]. Additional outcomes may be defined to allow for programs to distinguish themselves. Keep in mind that demonstration of the achievement of a program's outcomes should, by necessity, also demonstrate achievement of Criterion 3 (a)-(k) and MET program requirements [2]. A program's unique outcomes must be linked to the educational objectives in order to complete the continuous improvement loop. Both educational objectives and student outcomes should be measurable [3].

In this paper the direct assessment of core courses is used as a strong tool to measure the level of achievement of student outcomes. One can easily conclude that direct assessment is the key element to achieve the requirements of ABET Engineering Criteria.

\section{Establishing Student Outcome}

The Associate degree program in Manufacturing Engineering Technology channels the students' previous education and work experience to manufacturing related engineering careers. The Student outcomes are formulated based on the Educational Objectives described in Yanbu Industrial College catalog and the outcome requirements of ABET Criterion 3.

\section{Assessing Student Outcomes}

Assessment of the student outcomes is an ongoing process in the Mechanical Engineering Department. The program assessment is concerned with finding out the extent to which our courses are delivering the right outcomes. This is broadly implemented by direct and 
indirect assessment.

Assessment is defined as processes that identify, collect, and analyse data that can be used to evaluate achievements. Criterion 3 of the Engineering Accreditation Criteria deals with student outcomes (the famous 11 a-k ABET outcomes) and their assessment [3].

Since the curriculum is developed into courses, each course has to be divided into components, topics, and competencies that easily map into different student outcomes. These student outcomes, which can be measured at the time of graduation, indicate how the program prepares the graduates to achieve the professional and career accomplishments stated in the program objectives. Direct assessment of specialization courses is, hence, a strong way to measure the degree of achievement of student outcomes. Surveys and similar indirect measures can only provide secondary evidence and should be used in conjunction with direct measures of graded students' performance. The grades obtained by the students in course quizzes, exams, assignments, etc have to be converted to levels of achievement (assigned by weights) of course learning objectives. The mapping of these course learning objectives into student outcomes is used to obtain the degree of achievement of each student in the student outcomes of a particular course [4].

\section{Procedure}

The Student outcomes consist of nine components, covering all the requirements specified by ABET. The Course Learning Objectives are specified at the beginning of every course. Our assumption is, if all students can meet these Course Learning Objectives through direct course assessment, then the Student outcomes can be fully achieved satisfied. The following procedure is followed:

Step A. Linking Course learning outcomes to student outcomes

Stage 1. Involves mapping course learning outcomes (CLO) of all specialization courses to the Student outcomes (SO). When mapping, assign a weight $(1,2$ or 3$)$ according to the depth of the particular learning outcome. As an example [list, State, explain -1], [calculate, solve, derive, conduct -2], [Design, select, model -3] as shown in Table 1.

Table 1. Mapping of CLO to Student outcomes (SO).

\begin{tabular}{|c|c|c|c|c|c|c|c|c|c|c|}
\hline \multirow{2}{*}{ Specialization courses } & \multirow{2}{*}{ Credit Hours } & \multicolumn{9}{|c|}{ Student outcomes } \\
\hline & & $\mathbf{A}$ & B & $\mathbf{C}$ & D & $\mathbf{E}$ & $\mathbf{F}$ & $\mathbf{G}$ & $\mathbf{H}$ & I \\
\hline MET 201 & 2 & 3 & 0 & 3 & 2 & 2 & 0 & 1 & 0 & 0 \\
\hline MET211 & 1 & 0 & 1 & 1 & 2 & 3 & 0 & 0 & 1 & 1 \\
\hline MET212 & 2 & 0 & 0 & 1 & 1 & 1 & 2 & 3 & 1 & 3 \\
\hline MET213 & 3 & 3 & 2 & 0 & 0 & 0 & 0 & 1 & 1 & 2 \\
\hline MET 214 & 2 & 0 & 0 & 1 & 2 & 0 & 0 & 0 & 0 & 0 \\
\hline MET 217 & 2 & 0 & 1 & 2 & 0 & 1 & 2 & 1 & 1 & 0 \\
\hline Total & 14 & 9 & 5 & 10 & 8 & 8 & 5 & 6 & 4 & 6 \\
\hline Sum product & & 21 & 11 & 19 & 14 & 13 & 10 & 13 & 8 & 13 \\
\hline
\end{tabular}

Stage 2. Involves obtaining the Credit hours (column 2) of each course and multiplying it by the assigned mapped value.

Stage 3. Involves dividing the above result by the sum products [sum of credit hours multiplied by the assigned value] to get the fractional input as illustrated in Table 2. The important point to note is that the net value (total) for each of the student outcomes should be one. This is shared by many courses. It can be achieved and evaluated using direct assessment methods (like quizzes, assignments etc.).

Table 2. Share of each course on Student outcomes (SO).

\begin{tabular}{|c|c|c|c|c|c|c|c|c|c|}
\hline \multirow{2}{*}{ Specialization Courses (examples) } & \multicolumn{9}{|c|}{ Student outcomes shared by all courses through course learning objectives } \\
\hline & A & B & C & D & $\mathbf{E}$ & $\mathbf{F}$ & G & $\mathbf{H}$ & $\mathbf{I}$ \\
\hline MET 201 & 0.29 & 0.00 & 0.32 & 0.29 & 0.31 & 0.00 & 0.15 & 0.00 & 0.00 \\
\hline MET211 & 0.00 & 0.09 & 0.05 & 0.14 & 0.23 & 0.00 & 0.00 & 0.13 & 0.08 \\
\hline MET212 & 0.00 & 0.00 & 0.11 & 0.14 & 0.15 & 0.40 & 0.46 & 0.25 & 0.46 \\
\hline MET213 & 0.43 & 0.55 & 0.00 & 0.00 & 0.00 & 0.00 & 0.23 & 0.38 & 0.46 \\
\hline MET 214 & 0.00 & 0.00 & 0.11 & 0.29 & 0.00 & 0.00 & 0.00 & 0.00 & 0.00 \\
\hline MET 217 & 0.00 & 0.18 & 0.21 & 0.00 & 0.15 & 0.40 & 0.15 & 0.25 & 0.00 \\
\hline Total & 1.00 & 1.00 & 1.00 & 1.00 & 1.00 & 1.00 & 1.00 & 1.00 & 1.00 \\
\hline
\end{tabular}

Step B. Linking Direct Assessment Components to Student outcomes

Stage 4. For every course, some or all of the Student outcomes A to I are met by direct assessment.

Stage 5. For each course, construct a mapping matrix relating each Course Learning Outcomes to the different Student outcomes with the following score levels (1- slightly, 2-moderately and 3-strongly).

Determine the distribution of marks for the assessment components as shown Table 3. If the subject is theory only, allocate zero to all lab assessments and determine the 100 marks distribution on other activities.

Stage 6. For each assessment component calculate its share of marks (multiplying the assignment components share 
(mapped value/total of mapped values) by the average marks scored by the students in each assessment component and dividing by the maximum assigned marks for each assessment component as shown in (Table 4).

Table 3. Mapping direct assessment to SO for one course.

\begin{tabular}{|c|c|c|c|c|c|c|c|c|c|}
\hline \multirow{3}{*}{ SO } & \multirow{3}{*}{$\begin{array}{l}\text { Share for } \\
\text { each SO }\end{array}$} & \multicolumn{7}{|c|}{ Assessment Components } & \multirow{3}{*}{$\begin{array}{l}\text { Total of all } \\
\text { weights }\end{array}$} \\
\hline & & Quiz & Assignment & Tests & Lab work & Lab. Test & Final Lab & Final Theory & \\
\hline & & 5 & 5 & 20 & 10 & 10 & 15 & 35 & \\
\hline A & 0.29 & 2 & 1 & 1 & 3 & 2 & 2 & 3 & 14 \\
\hline $\mathrm{C}$ & 0.32 & 1 & 2 & 3 & 1 & 1 & 2 & 3 & 13 \\
\hline $\mathrm{D}$ & 0.29 & 1 & 2 & 3 & 1 & 3 & 3 & 3 & 16 \\
\hline $\mathrm{E}$ & 0.31 & 1 & 2 & 2 & 2 & 3 & 3 & 3 & 16 \\
\hline $\mathrm{G}$ & 0.15 & 1 & 1 & 1 & 2 & 2 & 3 & 3 & 13 \\
\hline
\end{tabular}

Table 4. SO for a single course.

\begin{tabular}{|c|c|c|c|c|c|c|c|c|c|c|}
\hline \multirow{3}{*}{ SO } & \multirow{3}{*}{$\begin{array}{l}\text { Share for } \\
\text { each SO } \\
\text { (Target) }\end{array}$} & Quiz & Assignment & Tests & Lab. work & Lab. Test & Final Lab & $\begin{array}{l}\text { Final theory } \\
\text { exam. }\end{array}$ & \multirow{3}{*}{$\begin{array}{l}\text { Effectiveness of } \\
\text { assessment on } \\
\text { obtaining SOs } \\
(\mathrm{Max}=1.0)\end{array}$} & \multirow{3}{*}{$\begin{array}{l}\text { Attained } \\
\text { SOs }\end{array}$} \\
\hline & & 5 & 5 & 20 & 10 & 10 & 15 & 35 & & \\
\hline & & $2 *$ & $4^{*}$ & $18^{*}$ & $8^{*}$ & $8^{*}$ & $13^{*}$ & $30^{*}$ & & \\
\hline $\mathrm{A}$ & 0.29 & 0.06 & 0.06 & 0.06 & 0.17 & 0.11 & 0.12 & 0.18 & 0.77 & 0.22 \\
\hline B & 0.00 & 0.00 & 0.00 & 0.00 & 0.00 & 0.00 & 0.00 & 0.00 & 0.00 & 0.00 \\
\hline $\mathrm{C}$ & 0.32 & 0.03 & 0.12 & 0.21 & 0.06 & 0.06 & 0.13 & 0.20 & 0.82 & 0.26 \\
\hline $\mathrm{D}$ & 0.29 & 0.03 & 0.10 & 0.17 & 0.05 & 0.15 & 0.16 & 0.16 & 0.82 & 0.23 \\
\hline $\mathrm{E}$ & 0.31 & 0.03 & 0.10 & 0.11 & 0.10 & 0.15 & 0.16 & 0.16 & 0.81 & 0.25 \\
\hline $\mathrm{F}$ & 0.00 & 0.00 & 0.00 & 0.00 & 0.00 & 0.00 & 0.00 & 0.00 & 0.00 & 0.00 \\
\hline $\mathrm{G}$ & 0.15 & 0.03 & 0.07 & 0.07 & 0.12 & 0.12 & 0.20 & 0.20 & 0.81 & 0.13 \\
\hline $\mathrm{H}$ & 0.00 & 0.00 & 0.00 & 0.00 & 0.00 & 0.00 & 0.00 & 0.00 & 0.00 & 0.00 \\
\hline I & 0.00 & 0.00 & 0.00 & 0.00 & 0.00 & 0.00 & 0.00 & 0.00 & 0.00 & 0.00 \\
\hline
\end{tabular}

Stage 7. Sum up all the mark shares (example for $\mathrm{SO}-\mathrm{A}$, the sum will be 0.29 if a student scores 100 marks in all assessments) to get the assessment effectiveness of program outcome.

Stage 8 . Calculate the attained SO by multiplying the assessment effectiveness of program outcome by the share of each SO (Target).

Stage 9. Repeat the steps 7 to 10 for all courses

Stage 10. Sum up all SO components A, B, C, D, E, F, G, $\mathrm{H}$ and $\mathrm{I}$ for all courses and insert it in the obtained column of
Table 4.

Stage 11. Fix the acceptable Outcomes Passing Ratio (OPR)

Stage 12. Return the results as presented in Table 5 for one course and Table 6 for the program.

The contents of Table 6 provide an insight into the degree achievement of students in fulfilling the Student outcomes. Corrective actions are to be taken based on the above results for continuous improvement of the program.

Table 5. Attained SO share for a single course.

\begin{tabular}{|c|c|c|c|c|c|c|c|c|c|}
\hline \multicolumn{10}{|c|}{ Obtained SOs for all students for a single course } \\
\hline & $\mathbf{A}$ & B & $\mathbf{C}$ & D & $\mathbf{E}$ & $\mathbf{F}$ & G & $\mathbf{H}$ & I \\
\hline Max (Target) & 0.29 & 0.00 & 0.32 & 0.29 & 0.31 & 0.00 & 0.15 & 0.00 & 0 \\
\hline Attained & 0.22 & 0.00 & 0.26 & 0.23 & 0.25 & 0.00 & 0.00 & 0.00 & 0.00 \\
\hline Needs correction & NO & NA & NO & $\mathrm{NO}$ & NO & NA & YES & NA & NA \\
\hline
\end{tabular}

Table 6. SO Assessment results.

\begin{tabular}{|c|c|c|c|c|c|}
\hline \multirow{2}{*}{ \# } & \multirow{2}{*}{$\begin{array}{l}\text { Student } \\
\text { outcomes }\end{array}$} & \multicolumn{4}{|c|}{ Assessment } \\
\hline & & Target & Acceptable OPR & Obtained & Needs correction \\
\hline 1 & A & 1.0 & 0.7 & 0.5 & Yes \\
\hline 2 & $\mathrm{~B}$ & 1.0 & 0.7 & 0.75 & No \\
\hline 3 & $\mathrm{C}$ & 1.0 & 0.7 & 0.54 & Yes \\
\hline 4 & $\mathrm{D}$ & 1.0 & 0.7 & 0.43 & Yes \\
\hline 5 & $\mathrm{E}$ & 1.0 & 0.7 & 0.89 & No \\
\hline 6 & $\mathrm{~F}$ & 1.0 & 0.7 & 0.9 & No \\
\hline 7 & G & 1.0 & 0.7 & 0.88 & No \\
\hline 8 & $\mathrm{H}$ & 1.0 & 0.7 & 0.91 & No \\
\hline 9 & $\mathrm{I}$ & 1.0 & 0.7 & 0.57 & Yes \\
\hline
\end{tabular}

\section{Documentation}

By analyzing retained documents and observations of events the evaluation team will be able to relate the display materials, i.e., course syllabi, sample student work, etc., to each Program Outcome.

The student performance in all courses is evaluated 
through quizzes, tests and assignments and the results are retained in Table 6. This result is compared with the acceptable level of achievement. The following procedures are used to refine the program.

1. Examine each attained Student outcomes value.

2. An average course achievement ratio (Outcomes Passing Ratio (OPR)) of $70 \%$ is set as the acceptable mark. If the total of each program outcome is below the acceptable OPR, look into all courses inputs contributing to that program outcome.

3. Redesign the course learning objective and contents

4. Assign new Credit hours (increase or decrease the Credit). Change the time exposure for course learning objective to attain the program outcome.

5. Redesign the assessment methods.

6. Suggest and implement possible changes to improve the students' performance.

\section{Input}

By the end of a semester each instructor should input the following data to YIC Computerized Marking System (CMS)

1. Assign a weight to Course Learning Outcomes (CLO) that is linked to Student outcomes (Table 1).

2. Number of students in all courses

3. Direct Assessment methods (components like quizzes, assignment etc.)

4. Distribution of points (Marks) for each Assessment component

5. Assign weight for every assessment components (Table 3).

6. Average points scored by the students for each component for every course

7. Acceptable Outcomes Passing Ratio (OPR).

\section{Output}

1. Student outcomes shared by each course

2. Final result of student outcomes shared by each course

3. Number of courses in which the Student outcomes are not met

4. Final result of student outcomes obtained from all courses (A to I)

5. Correction strategy for all courses

\section{Conclusion}

A simplified method is proposed for using the results of course level direct assessment to evaluate the students' achievement of Student outcomes. The proposed approach is used to obtain a weighed average of achievement of student outcomes by a combination of learning depth and learning coverage in different specialization courses. Corrective actions can be formulated based on the end results. Indirect assessments can be used to support the above findings and to improve or modify course learning objectives.

\section{References}

[1] Criteria for Accrediting Engineering Programs, Effective for Evaluations During the 2006-2007 Accreditation Cycle, Engineering Accreditation Commission, ABET Inc., Oct. 2005. Downloaded from http://www.abet.org.

[2] Felder, R. M., and Brent, R. "Designing and Teaching Courses to Satisfy the ABET Engineering Criteria", Journal of Engineering Education, 92 (1), 7-25, 2003.

[3] Al-Bahi, A. M. "Exposure Matrix - An Approach to Evaluate Student outcomes Using Course Level Direct Assessment", Paper \# 1059, the 2nd international conference on engineering education \& training (ICEET-2), Kuwait, 2007.

[4] Al-Bahi, A. M., "HI-CLASS - a Handy Instrument for Course Level Assessment," Paper \# 1058, the 2nd International Conference on Engineering Education \& Training (ICEET-2), Kuwait, 200. 